RESENHA

\title{
Democracia e Ecomunitarismo
}

Democracy and Ecomunitarism

Claudinei Aparecido de Freitas da SILVA*

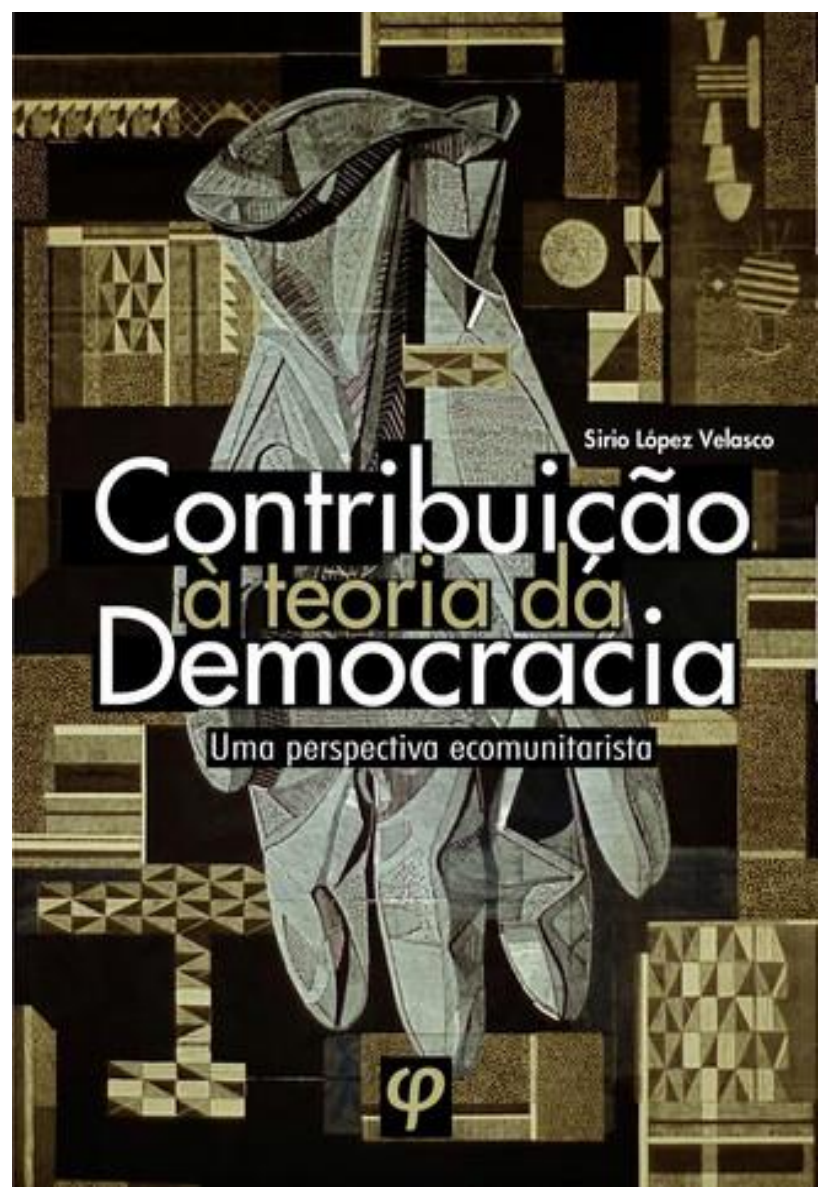

RESENHA/ BOOK REVIEW

VELASCO, Sirio López. Contribuição à teoria da democracia: uma perspectiva ecomunitarista. Porto Alegre: FI, 2017. 150 p.

* Professor. Pós-Doutor. Atua nos Cursos de Graduação e de Pós-Graduação (Stricto Sensu) em Filosofia da Universidade Estadual do Oeste do Paraná (UNIOESTE), Campus Toledo. Rua Arnaldo Mânica, $\mathrm{n}^{\circ}$ 40, BNH, Tocantins, CEP: 85903-360, Toledo (PR). E-mail: <cafsilva@uol.com.br>. ORC ID: $<$ http://orcid.org/o0oo-0002-9321-5945>. 
Em 2017, o leitor é brindado, em dose dupla, por um significativo projeto editorial emplacado pela Editora FI de Porto Alegre: Ideas y Experiencias de la Democracia: una mirada ecomunitarista e Contribuição à Teoria da Democracia: uma perspectiva ecomunitarista, de Sirio López Velasco. O segundo trabalho corresponde, em edição vernácula, a uma versão mais ampla e, portanto, completa em relação ao primeiro, que somara 87 páginas, em castelhano. $\mathrm{O}$ autor consolida, em mais essa obra, uma longa trajetória intelectual. Prova inconteste disso é a sua recorrente presença na cena cultural latino-americana, bem como, em particular, na esfera pública do debate político-social no país. Mais que um simples teórico do pensamento, Velasco encarna verdadeiramente a figura do intelectual engajado, condição, como se sabe, cada vez mais rara em nossa cultura acadêmica. É reconhecendo a dimensão maior desse espírito que o livro se inscreve no coração mesmo da história, avivando dois temas especialmente caros ao seu autor: democracia e ecomunitarismo!

São tais implicações conceituais que Sirio explora, sob uma fina e rigorosa análise, propondo-se a um olhar não somente crítico, mas propositivo. É a crise histórica da experiência democrática que sintomaticamente se diagnostica à luz do dia via o corolário conceito de ecomunitarismo, originalmente formulado por ele. Para uma melhor compreensão dessa proposta, situemos, ao menos, alguns de seus aspectos que nos parecem mais significativos.

Velasco, inicialmente, procede a um recenseamento crítico de inúmeras concepções de democracia historicamente instituídas, desde a sua matriz clássica grega até a soviética mediada pela versão liberal burguesa vigente em nossos dias. É assim que o livro faz um balanço geral de cada um desses modelos, identificando tanto suas virtudes quanto seus vícios. Salvo melhor juízo, a real democracia que se almeja não parece estar suficientemente contemplada nesses distintos registros, o que cria uma ocasião oportuna de transcendê-los rumo a uma perspectiva, como prenuncia Sirio, "pós-capitalista". Qual seria, enfim, esse horizonte entrevisto? Nosso autor acena o caminho: O que se propõe é uma teoria da democracia em ótica ecomunitarista. Por isso, reagindo contra as concepções democráticas que aceitam explícita ou implicitamente o capitalismo, trata-se de avançar numa direção diametralmente oposta, fundada na dedução argumentativa de três normas fundamentais da ética formuladas por Velasco nos seguintes termos: i) a de lutar para a realização de nossa liberdade individual de decisão; ii) de realizar essa liberdade em busca de respostas consensuais com os outros e iii) de preservar-regenerar a saúde da natureza humana e não humana. $\mathrm{O}$ que se tem como pano de fundo é uma tríplice aliança ético-normativa, condição indispensável para se pensar uma nova instância de práxis democrática baseada na liberdade de escolha e, é claro, movida pela busca de respostas compartilhadas entre liberdades cooperantes. A construção de uma via consensual jamais prescinde dessa gramática profunda intersubjetivamente válida à luz do discurso.

Qual então o núcleo desse contributo? Ele é balizado por Velasco (2017, p. 10) como se segue:

[...] caracterizamos o ecomunitarismo como una ordem utópica socioambiental póscapitalista (irrealizável no seu todo, mas indispensável guia para que a ação cotidiana 
tenha um sentido histórico claramente definido) composto por várias dimensões concomitantes e combinadas.

Entre essas dimensões, quatro merecem atenção, radicadas, sempre, a partir das três normas éticas acima deduzidas: primeiramente, uma economia ecológica e sem patrões, na qual os produtores livremente associados contribuam conforme sua capacidade e necessidade. Em segundo lugar, uma educação ambiental problematizadora capaz de promover uma rica vida intercultural e artística aliada também a uma educação sexual libertadora e um espírito esportivo mais formativo e cooperativo. Em terceiro lugar, uma comunicação simétrica, que ponha em mãos de meios comunitários e/ou públicos (geridos comunitariamente) os atuais latifúndios da grande mídia privada. E, em quarto, uma política coletiva e solidária baseada na maior dose possível de democracia direta e participativa na qual os espaços indispensáveis de democracia representativa que se mantenham sejam confiados a ocupantes rotativos e revogáveis a qualquer momento pelos seus eleitores (Cf. VELASCO, 2017, p. 10-11).

Ora, é esse contexto multidimensional que a democracia liberal burguesa perde de vista como horizonte último, uma vez que se funda numa retórica puramente abstrata que não leva em conta, em seu conjunto, aquelas três normas básicas irrevogáveis. $O$ ponto nevrálgico é que a democracia liberal viola o direito de argumentar e, com isso, escapa-lhe o sentido mais pleno da democracia "[...] como sendo o governo do povo, pelo povo e para o povo" (VELASCO, 2017, p. 11), tão precisamente definido por Lincoln. Assim, toda norma exógena pétrea (de cariz moral, religiosa ou jurídica) arbitrada à revelia do consenso termina por hipostasiar a ideia mais própria de democracia, reduzindo-a a uma mera ficção demagógica e, portanto, ideológica.

Pois bem. O que a democracia ecomunitarista postula é que, para além de interesses financeiros, personalistas ou de lobbies egoístas, há um interesse maior a ser preservado: a soberania popular. Tal interesse transcende, inclusive, organizações como ONGs e partidos políticos. A crise da ideia de partido, p. ex., assim se justifica:

[...] a permanência dos atuais Partidos políticos não aparece como uma necessidade inerente ao ecomunitarismo; isto porque uma vez superada a divisão entre as classes, a rica diversidade humana pode se expressar através das organizações sociais e dos meios de comunicação [...] sem a necessidade dos Partidos na sua forma atual. (VELASCO, 2017, p. 126).

Velasco admite que, com a desconstrução da ideia de partido, se reconfigura também a noção de líder, à medida que este, antes deve "dirigir obedecendo", isto é, não cabe decidir por si mesmo sem deixar de ouvir (consultar) os demais. É sob esse contexto mais amplo que as mídias sociais exercem um papel importante na democracia ecomunitarista, pois "[...] a rede não admite chefes fixos, mas lideranças provisórias-rotativas (sic)" (VELASCO, 2017, p. 127). O que se constata é que “[...] as redes demonstram hoje que a atividade 'política' é maior do que a política partidária, recuperando seu sentido grego de 'organização da cidadeestado em mãos do conjunto dos cidadãos"” (VELASCO, 2017, p. 127).

De todo modo, Velasco reconhece que fenômenos como a burocracia, a corrupção, o culto à personalidade e a prática eleitoreira nada mais são do que sintomas dos ideais democráticos

Argum., Vitória, v. 10, n.1, p. 309-313, jan./abr. 2018. 
liberais. A superação desses problemas só é possível mediante uma decisão comunitária de prioridades e ações em seu livre e legítimo exercício intuídas no âmbito das condições éticoargumentativas antes postuladas. Da mesma forma, a tradicional divisão entre os três poderes se desconstrói completamente, uma vez que

[...] todas as decisões e ações das três esferas repousam nas decisões diretas por parte de cada cidadão e seus sucessivos coletivos comunitários; ora, essa autoridade se mantém e renova em cada caso através dos mecanismos participativos, e do controle da ação e eventual revogação sobre os representantes provisórios previamente eleitos (VELASCO, 2017, p. 132).

É, pois, na instância de uma democracia participativa que se reconhece outra dinâmica estrutural. Sob esse aspecto, o ecomunitarismo projeta uma alternativa premente de emancipação ecológica, quer dizer, "[...] a ameaça de um holocausto ecológico capaz de exterminar a humanidade inteira é uma situação absolutamente inédita na história da espécie humana” (VELASCO, 2017, p. 34). Tal quadro se desenha em função da lógica extrativista do capital, cujos desastres atingem proporções sem precedentes na história. Assim, a superação desse quadro só se torna exequível via uma educação ambiental ecomunitarista ou, se se quiser, "irrenunciavelmente socioambiental" e a partir de um espaço compartilhado, de cuja gestão pública cada cidadão é membro ativo.

É nessa direção que o autor recupera alguns registros, a título ilustrativo, de vivências interculturais:

Hoje resulta claro, especialmente no caso da A. Latina, que a democracia em perspectiva ecomunitarista não poderá se fundamentar unicamente em fontes ocidentais, mas, pelo contrário, deverá incorporar dialogicamente as contribuições positivas oriundas de outras fontes (particularmente as indígenas, negras e orientais). As culturas indígena e negra têm resistido por 500 anos à Conquista para nos legar sua lúcida perspectiva cosmocêntrica socioambiental. (VELASCO, 2017, p. 125).

À primeira vista, talvez fosse de supor que esse movimento reflexivo parecesse "utópico", num sentido ingenuamente romântico de promover transformações sociais. Ou, ainda, "utópico" como mero recurso especulativo, isto é, recurso retórico filosófico. Ora, o livro de Velasco é "utópico", sim, mas numa orientação radicalmente diversa. Uma de suas virtudes consiste em demonstrar, à luz da experiência histórica, a possibilidade de mudança, ou seja, de revolução e criação em que nós nos investimos dialeticamente como cossujeitos históricos, transcendendo, pois, todo darwinismo social do homem como espécie natural. É sob essa acepção que a democracia, em perspectiva ecomunitarista, é "utópica", ou seja, racionalmente circunscrita como ideal a ser perseguido e não como simples crença ou ato de fé. Trata-se, como reconhece o autor, de um estágio de reflexão jamais conclusivo e, por isso mesmo, provisório, uma vez que se mantém permanentemente aberto à crítica. 
Claudinei Aparecido de Freitas da SILVA Professor dos Cursos de Graduação e de Pós-Graduação (Stricto Sensu) em Filosofia da UNIOESTE - Campus Toledo com Estágio Pós-Doutoral pela Université Paris 1 Panthéon-Sorbonne (2011/2012). Escreveu "A carnalidade da reflexão: ipseidade e alteridade em MerleauPonty" (São Leopoldo, RS, Nova Harmonia, 2009) e "A natureza primordial: Merleau-Ponty e o 'logos do mundo estético”" (Cascavel, PR, Edunioeste, 2010). Organizou “Encarnação e transcendência: Gabriel Marcel, 40 anos depois" (Cascavel, PR, Edunioeste, 2013), "Merleau-Ponty em Florianópolis" (Porto Alegre, FI, 2015), "Kurt Goldstein: psiquiatria e fenomenologia" (Cascavel, PR, Edunioeste, 2015), Festschrift aos 20 anos do Simpósio de Filosofia Moderna e Contemporânea da UNIOESTE (Cascavel, PR, Edunioeste, 2016), em parceria com Franco Riva, Compêndio Gabriel Marcel (Cascavel, PR: Edunioeste, 2017) e "A fenomenologia no oeste do Paraná: retrato de uma comunidade" (Toledo, PR, Vivens, 2018). 